Supporting Information for:

\title{
Positive Identification of DNA Cleavage by CRISPR-Cas9 Using Pyrene Excimer Fluorescence To Detect a Subnanometer Structural Change
}

Jinho Park, ${ }^{\dagger}$ Keewon Sung, ${ }^{\dagger}$ So Young Bak,${ }^{\dagger}$ Hye Ran Koh,,${ }^{*,}$ and Seong Keun Kim ${ }^{*, \dagger}$

† Department of Chemistry, Seoul National University, Seoul 08826, Republic of Korea.

$\ddagger$ Department of Chemistry, Chung-Ang University, Seoul 06974, Republic of Korea.

*e-mail: seongkim@snu.ac.kr or hrkoh@cau.ac.kr 
Protein expression and purification. Streptococcus pyogenes wild-type Cas9 (wtCas9) and D10A/H840A-mutated, catalytically inactive Cas9 (dCas9) were used in this experiment. All expression and purification procedures were repeated as previously described. ${ }^{1}$ In details, Cas 9 proteins were expressed in E. coli. NiCo21 (DE3) strain (LumiMac) using the expression plasmid pET28-a(+) for 18 hours at $18{ }^{\circ} \mathrm{C}$ after initiation of $0.2 \mathrm{mM}$ IPTG induction. Saturated $E$. coli. was recovered with centrifugation and sonicated in lysis buffer $(\mathrm{pH} 8.0,300 \mathrm{mM} \mathrm{NaCl}, 50 \mathrm{mM}$ $\mathrm{NaH}_{2} \mathrm{PO}_{4}$, and $10 \mathrm{mM}$ imidazole). The expressed Cas9 protein containing a His-tag at the $\mathrm{N}$ terminus was equilibrated with Ni-NTA agarose resins (Qiagen) and loaded into the column. The column was washed with wash buffer $\left(\mathrm{pH} 8.0,300 \mathrm{mM} \mathrm{NaCl}, 50 \mathrm{mM} \mathrm{NaH}_{2} \mathrm{PO}_{4}\right.$, and $20 \mathrm{mM}$ imidazole) and eluted by elution buffer $\left(\mathrm{pH} 8.0,300 \mathrm{mM} \mathrm{NaCl}, 50 \mathrm{mM} \mathrm{NaH}_{2} \mathrm{PO}_{4}\right.$, and $250 \mathrm{mM}$ imidazole). The eluate was dialyzed against dialysis buffer $(10 \mathrm{mM}$ Tris- $\mathrm{HCl} \mathrm{pH} \mathrm{7.4,} 300 \mathrm{mM} \mathrm{NaCl}$, $0.1 \mathrm{mM}$ EDTA, $1 \mathrm{mM}$ DTT, and 10\% (v/v) glycerol) and concentrated using Amicon Ultra centrifugal filter-100 kDa (Millipore) when necessary. After the dialysis and filtration, the concentration and purity of Cas 9 protein were measured by the Bradford assay (Bio-Rad) and SDS-PAGE, respectively. Finally, proteins were diluted and stored at $-20{ }^{\circ} \mathrm{C}$ in the storage buffer (10 mM Tris- $\mathrm{HCl} \mathrm{pH} \mathrm{7.4,} 300 \mathrm{mM} \mathrm{NaCl}, 0.1 \mathrm{mM}$ EDTA, $1 \mathrm{mM}$ DTT, and 50\% (v/v) glycerol). All purification procedures were performed at $4{ }^{\circ} \mathrm{C}$.

Preparation of oligo nucleotides. All DNA and RNA oligonucleotides were purchased from Bioneer and Integrated DNA Technologies. All DNA and RNA oligonucleotides were purified with HPLC. DNA substrates used in this work have the same sequence except for some necessary modifications according to the experiment. Introduction of mismatched sequences between DNA and RNA was done by changing the sequence of RNA. The sequences for DNA and RNA samples are listed in Table S1.

Fluorescence measurements. Unless otherwise noted, all fluorescence measurements were performed using a fluorimeter (QM-4/2005SE, Photon Technology) in reaction buffer (with final

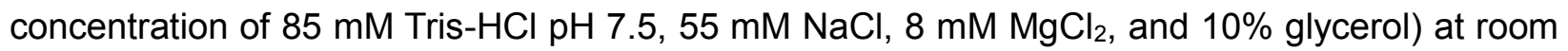
temperature. For imaging the equilibrium state, $400 \mathrm{nM}$ of tracrRNA was pre-incubated with $1 \mathrm{uM}$ of crRNA and wtCas9 (or dCas9) for $5 \mathrm{~min}$ at $37^{\circ} \mathrm{C} .200 \mathrm{nM}$ of pyrene-labeled DNA was added and incubated for more than $10 \mathrm{~min}$ at room temperature. The fluorescence emission spectrum was measured over the emission wavelengths of $370-550 \mathrm{~nm}$ upon photo-excitation at $350 \mathrm{~nm}$, followed by the subtraction of Raman scattering signal from water. The intensity of pyrene excimer emission was defined as the integrated area between $430-550 \mathrm{~nm}$. The temporal evolution of the pyrene excimer emission was measured under the following conditions: $400 \mathrm{nM}$ of tracrRNA was pre-incubated with $1 \mathrm{uM}$ of wtCas 9 (or dCas9) for $5 \mathrm{~min}$ at $37{ }^{\circ} \mathrm{C} ; 200 \mathrm{nM}$ of pyrene-labeled DNA and $1 \mathrm{uM}$ of crRNA were also prepared at room temperature; the temporal evolution of the excimer emission was recorded at the excitation and emission wavelengths of $350 \mathrm{~nm}$ and 460 $\mathrm{nm}$, respectively, after addition of Cas 9 complex into a cuvette containing DNA and crRNA. The data acquisition time was set to $500 \mathrm{~ms}$ and mixing was done manually with the dead-time of about $1 \mathrm{~s}$. For Figure 2(b)-(c) and Table S2, the concentration of pyrene-labeled DNA was reduced to $20 \mathrm{nM}$ and the concentration of Cas 9 complex was varied from 50 to $400 \mathrm{nM}$. 
DNA binding assay. A protein-induced fluorescence enhancement (PIFE) assay was used to measure the binding affinity between DNA and Cas9 protein. ${ }^{2} 10 \mathrm{nM}$ of Cy3-labelled DNA was incubated at room temperature for $30 \mathrm{~min}$ in reaction buffer without $\mathrm{Mg}^{2+}$ as the concentration of the wtCas9/gRNA complex was sequentially increased $(0.1,1,3,10,30,100,300$, and $800 \mathrm{nM})$. PIFE (\%) was defined as $\frac{I-I_{\min }}{I_{\max }-I_{\min }} \times 100(\%)$ where $I_{\min }$ and $I_{\max }$ are the minimum and maximum fluorescence intensities in the range of $550-700 \mathrm{~nm}$, respectively. The dissociation constant $\mathrm{K}_{\mathrm{D}}$, defined as $\mathrm{K}_{\mathrm{D}}=\frac{k_{o f f}}{k_{o n}}$, was obtained by fitting the PIFE data (\%) against the corresponding concentration of the Cas9:gRNA complex $[E]$ using the equation, PIFE (\%) = $\frac{1}{2[S]_{0}}\left[\left([S]_{0}+[E]+K_{D}\right)-\sqrt{\left([S]_{0}+[E]+K_{D}\right)^{2}-4[E][S]_{0}}\right]$, where $[S]_{0}$ represents the concentration of the DNA probe. ${ }^{3}$

DNA cleavage assay. Cy5-labeled DNA (referred to be 'unlabeled DNA' in this work, indicating that it is not pyrene-labeled) was used as a probe for DNA cleavage assay. The saturated level of cleavage efficiency for wtCas9/gRNA was obtained in the following conditions: $400 \mathrm{nM}$ of tracrRNA was pre-incubated with $1 \mathrm{uM}$ of crRNA and wtCas 9 for 5 min at $37{ }^{\circ} \mathrm{C}$; $200 \mathrm{nM}$ of unlabeled or pyrene-labeled DNA was added and incubated for $15 \mathrm{~min}$ at room temperature; the final reactants were removed and quenched by mixing with an equal volume of $2 x$ gel loading buffer (70\% foramide, 1\% SDS, 50 mM EDTA, and bromophenol blue dye), followed by denaturing at $55{ }^{\circ} \mathrm{C}$ for $5 \mathrm{~min}$. The time-resolved cleavage assay was carried out under the following conditions: $400 \mathrm{nM}$ of tracrRNA and $1 \mu \mathrm{M}$ of wtCas 9 protein was pre-incubated for 5 min at $37^{\circ} \mathrm{C}$ and mixed with $200 \mathrm{nM}$ of unlabeled or pyrene-labled DNA and $1 \mu \mathrm{M}$ of crRNA; reactants were removed at various time points and quenched by mixing with an equal volume of $2 x$ gel loading buffer ( $70 \%$ foramide, 1\% SDS, 50 mM EDTA, and bromophenol blue dye), followed by denaturing at $55{ }^{\circ} \mathrm{C}$ for $5 \mathrm{~min}$. All cleaved products were resolved by $20 \%$ denaturing UREA PAGE gel at 55 ${ }^{\circ} \mathrm{C}$ and visualized by Cy5 imaging using G:BOX (SYNGENE). All DNA cleavage experiments were conducted in reaction buffer at room temperature.

Single-turnover kinetics model. Due to the unique property of Cas9 not releasing the DNA product even after cleavage, single-turnover kinetics, rather than Michaelis-Menten kinetics, was used to analyze the 2-step kinetic model:

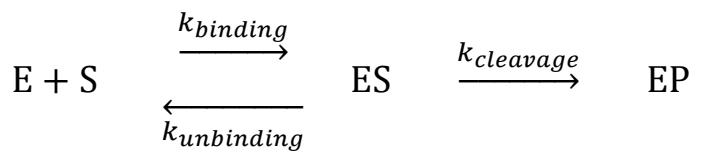

where $E, S$, and $P$ represent wtCas9/gRNA, DNA substrate, and DNA cleavage product, respectively. The conservation of total DNA substrate should satisfy

$$
[S]_{0}=[S]+[E S]+[E P]
$$

where $[S]_{0}$ represents the total amount of DNA substrate. Assuming a negligible amount of 
change in $[E S]\left(\frac{d[E S]}{d t} \approx 0\right)$,

$$
k_{\text {binding }}[E][S]-k_{\text {unbinding }}[E S]-k_{\text {cleavage }}[E S]=0
$$

and

$$
\mathrm{K}_{\mathrm{M}}^{\prime}=\frac{k_{\text {unbinding }}+k_{\text {cleavage }}}{k_{\text {binding }}}=\frac{[E][S]}{[E S]} .
$$

Because

$$
[S]=[S]_{0}-[E S]-[E P]
$$

and

$[E S]$ can be written as

$$
[E] \approx[E]_{0} \text { when }[E]_{0} \gg[S],
$$

The rate of formation of $[E P]$ is given by

$$
[E S]=\frac{[S]_{0}-[E P]}{\frac{\mathrm{K}_{\mathrm{M}}^{\prime}}{[E]_{0}}+1} .
$$

$$
v=\frac{d[E P]}{d t}=k_{\text {cleavage }}[E S]=\frac{[S]_{0}-[E P]}{\frac{\mathrm{K}_{\mathrm{M}}^{\prime}}{[E]_{0}}+1}=k_{\text {obs }}\left([S]_{0}-[E P]\right)
$$

where $k_{o b s}$ is defined as

$$
k_{\text {obs }}=\frac{k_{\text {cleavage }}}{\frac{\mathrm{K}_{\mathrm{M}}^{\prime}}{[E]_{0}}+1}
$$

Finally,

$$
[E P]=[S]_{0}\left(1-e^{-k_{o b s} t}\right) \cdots \text { Eq. (1) }
$$

and

$$
\frac{1}{k_{\text {obs }}}=\frac{1}{k_{\text {cleavage }}}+\frac{\mathrm{K}_{\mathrm{M}}^{\prime}}{k_{\text {cleavage }}} \frac{1}{[E]_{0}} \cdots \text { Eq. (2) }
$$

is obtained. The value of $k_{o b s}$ is obtained by fitting the temporal evolution of the pyrene excimer emission upon addition of wtCas9/gRNA to the single-exponential function and the values of $k_{\text {cleavage }}$ and $K_{M}^{\prime}$ were obtained by fitting $1 / k_{\text {obs }}$ as a linear function of $1 /[E]_{0}$.

Transient-state kinetics model. To address the effects of intermediate state for data such as given by Figure S9, transient-state kinetics was employed. The kinetics is described by a 2-step model:

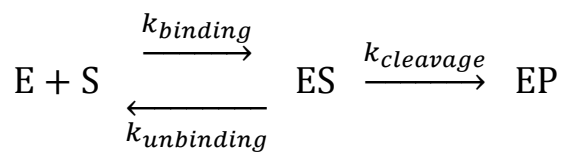

where E, S, and P indicate Cas9 protein, DNA substrate, and DNA cleavage product, respectively. Kinetics for each species can be described as

$$
\begin{gathered}
\frac{d[S]}{d t}=-k_{\text {binding }}[E][S]+k_{\text {unbinding }}[E S] \cdots(1) \\
\frac{d[E S]}{d t}=k_{\text {binding }}[E][S]-k_{\text {unbinding }}[E S]-k_{\text {cleavage }}[E S] \cdots(2),
\end{gathered}
$$

and 


$$
\frac{d[E P]}{d t}=k_{\text {cleavage }}[E S] \cdots(3)
$$

The conservation of total DNA substrate is dictated by

$$
\frac{d[S]}{d t}+\frac{d[E S]}{d t}+\frac{d[E P]}{d t}=0 \cdots(4) .
$$

By substituting Eqn (1) through (3) into Eqn (4), kinetics for [ES] and [EP] can be rearranged to

$$
\begin{aligned}
& \frac{d^{2}[E S]}{d t^{2}}+\left(k_{\text {binding }}+k_{\text {unbinding }}+k_{\text {cleavage }}\right) \frac{d[E S]}{d t}+\left(k_{\text {binding }} k_{\text {cleavage }}\right)[E S]=0 \\
& \text { and } \frac{d^{2}[E P]}{d t^{2}}+\left(k_{\text {binding }}+k_{\text {unbinding }}+k_{\text {cleavage }}\right) \frac{d[E P]}{d t}+\left(k_{\text {binding }} k_{\text {cleavage }}\right)[E P]=0 .
\end{aligned}
$$

The second order differential equation has a solution of $[\mathrm{ES}]=A^{\prime}{ }_{0}+A^{\prime}{ }_{1} e^{-k_{o b s, 1} t}+A^{\prime}{ }_{2} e^{-k_{o b s, 2} t}$ and $[\mathrm{EP}]=A^{\prime \prime}{ }_{0}+A^{\prime \prime}{ }_{1} e^{-k_{o b s, 1} t}+A^{\prime \prime}{ }_{2} e^{-k_{o b s, 2} t}$.

Thus, real-time measurement of the change in pyrene excimer fluorescence induced by [ES] + [EP] can be described by bi-exponential equation,

$$
[\mathrm{ES}]+[\mathrm{EP}]=A_{0}+A_{1} e^{-k_{o b s, 1} t}+A_{2} e^{-k_{o b s, 2} t} \ldots
$$

where

$$
k_{o b s, 1}+k_{o b s, 2}=k_{\text {binding }}[\mathrm{E}]+k_{\text {unbinding }}+k_{\text {cleavage }} \cdots
$$

and

$$
k_{o b s, 1} k_{o b s, 2}=k_{\text {binding }} k_{\text {cleavage }}[\mathrm{E}] \cdots(7) \text {. }
$$

The values of $k_{\text {binding }}, k_{\text {unbinding }}$, and $k_{\text {cleavage }}$ can be obtained by linear fitting of $k_{o b s, 1}+$ $k_{o b s, 2}$ and $k_{o b s, 1} k_{o b s, 2}$ against the corresponding [E]. 
(a)
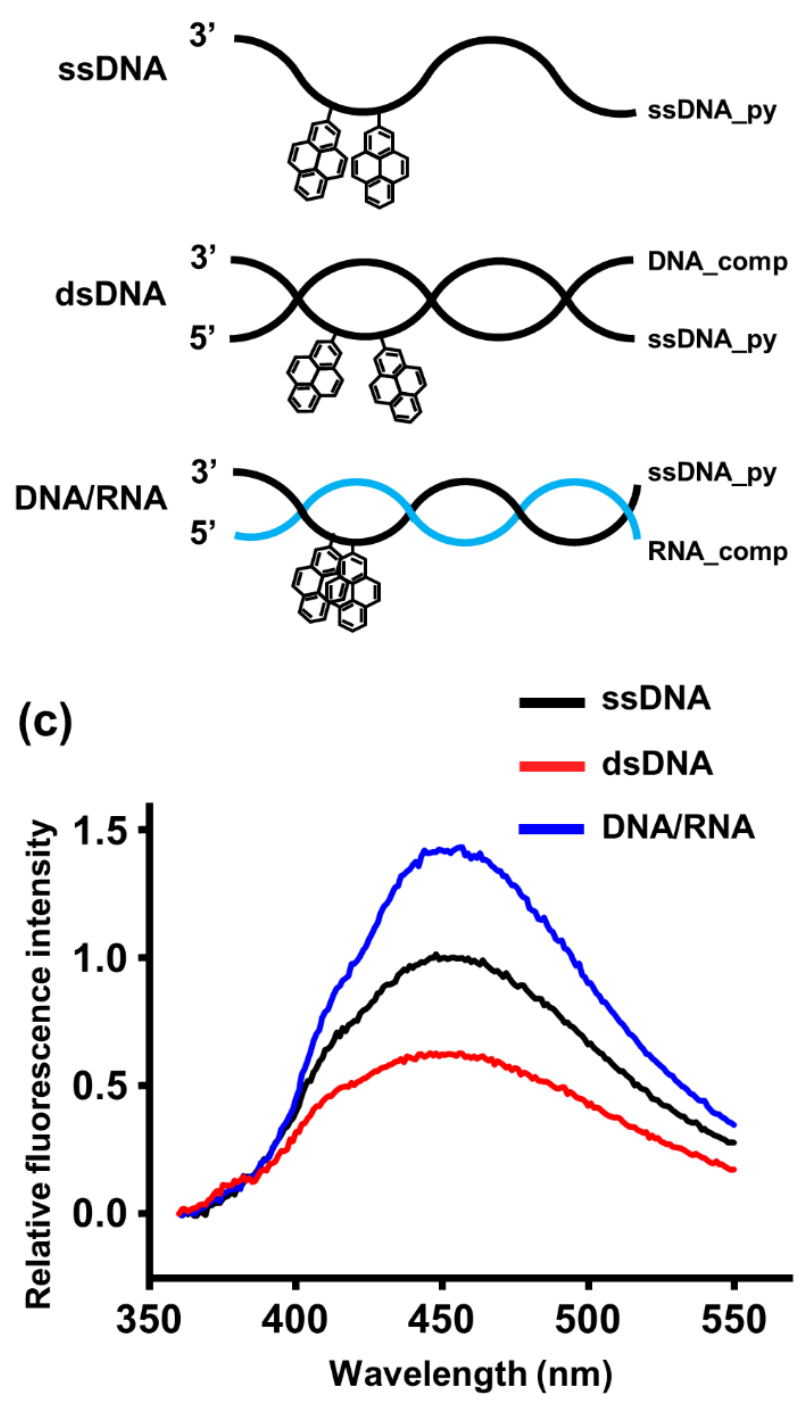

(b)

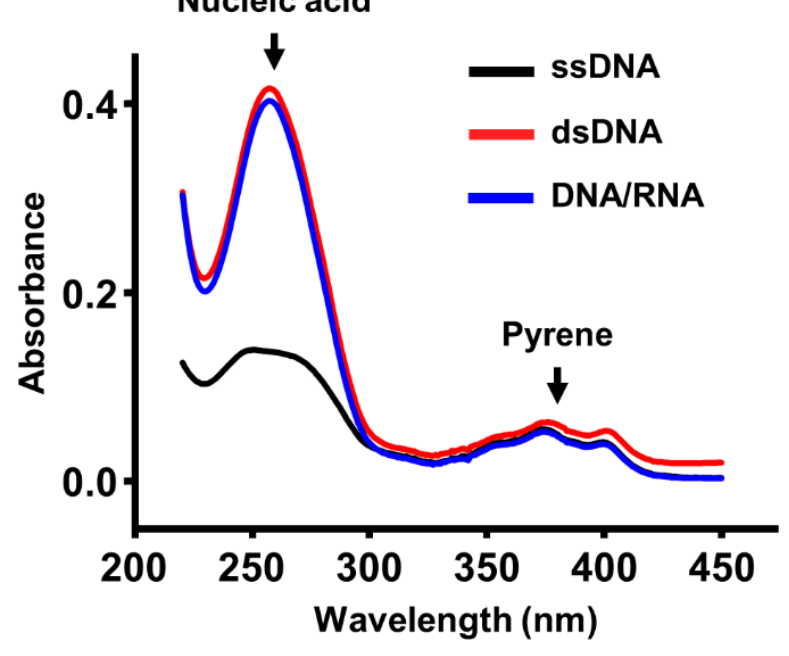

(d)

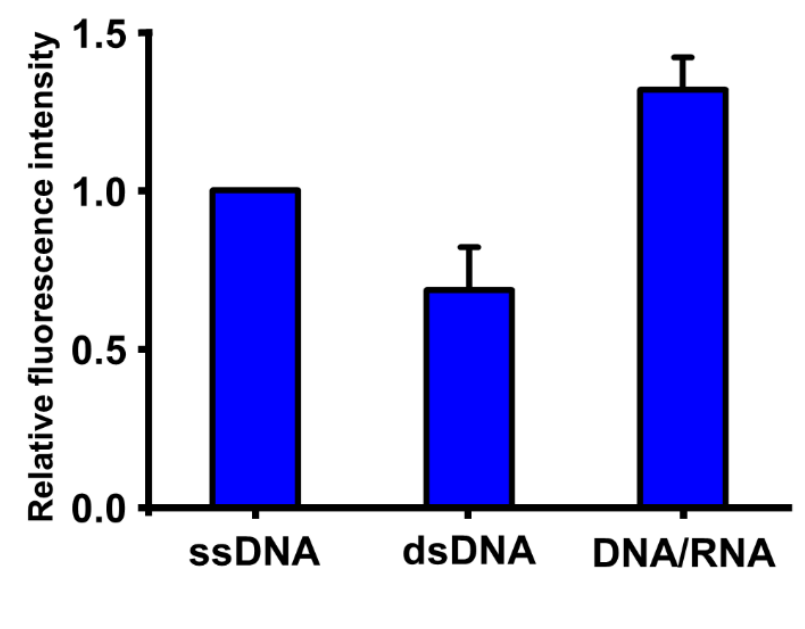

Figure $\mathbf{S 1}$ (a) Schematic representation of pyrene-labeled SSDNA, dsDNA and DNA/RNA. (b) Absorption spectra of pyrene-labeled ssDNA, dsDNA and DNA/RNA. Absorbance of pyrene molecules was not affected by structural difference of nucleic acids. (c-d) Relative intensities of excimer emission with respect to the intensity of SSDNA, which is consistent with what we can expect from the structure of each nucleic acid. ${ }^{4,5}$ Excimer formation is hindered as the ssDNA is hybridized to the more structurally rigid dsDNA, which results in the reduction in the intensity of excimer emission. On the other hand, the A-form helix of the DNA/RNA heteroduplex has a more compact structure, which may bring the two pyrene moieties closer than in dsDNA or ssDNA, leading to the increase in the intensity of excimer emission. The absorption and excimer emission spectra were measured under the following conditions: 1 uM of pyrene-labeled ssDNA was 
hybridized with $2 \mathrm{uM}$ of the corresponding complementary strand in reaction buffer. For figure S1 (c-d), the excitation wavelength was $340 \mathrm{~nm}$ and the intensity of excimer emission was defined as the integrated area between $430-550 \mathrm{~nm}$. Error bars, s.d.; $\mathrm{n}=3$. 

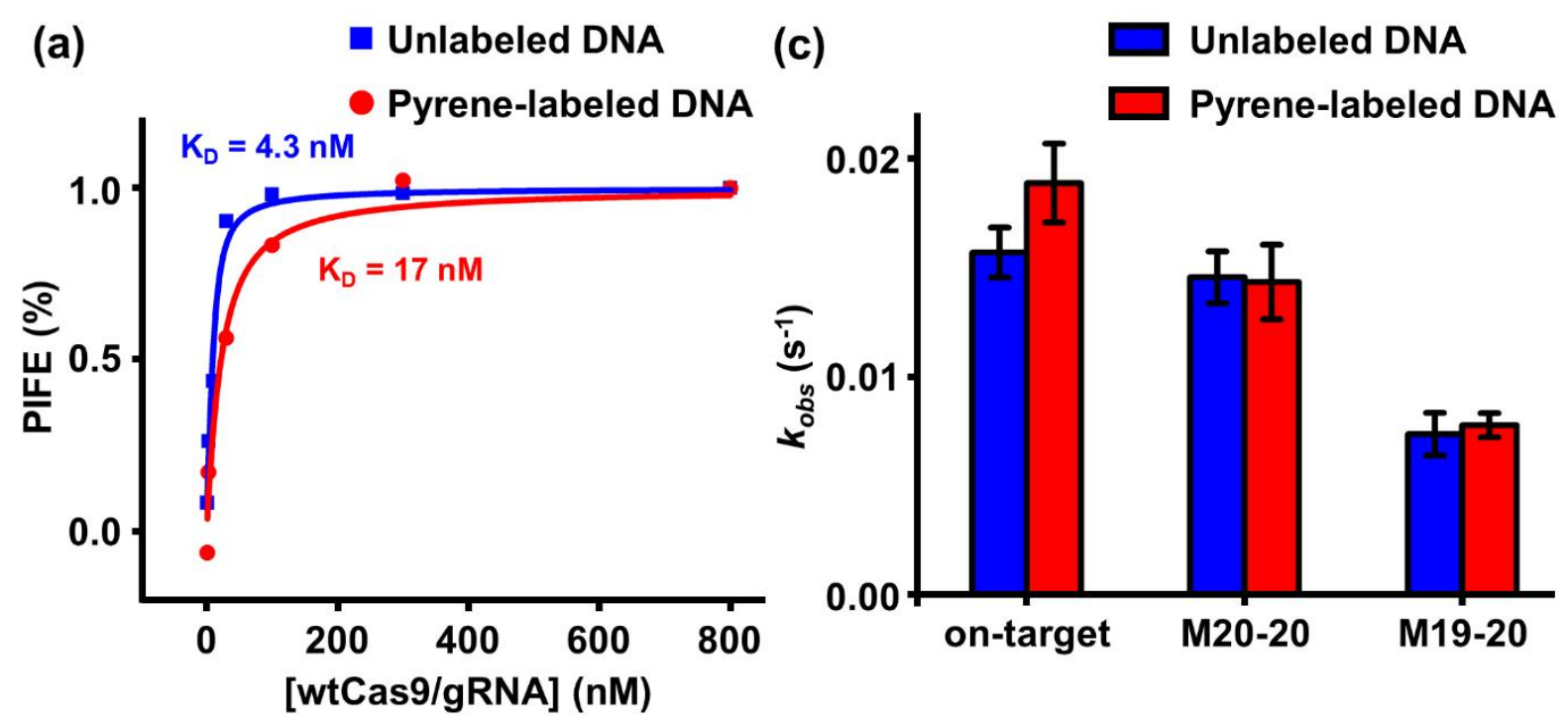

(b) Time (s)
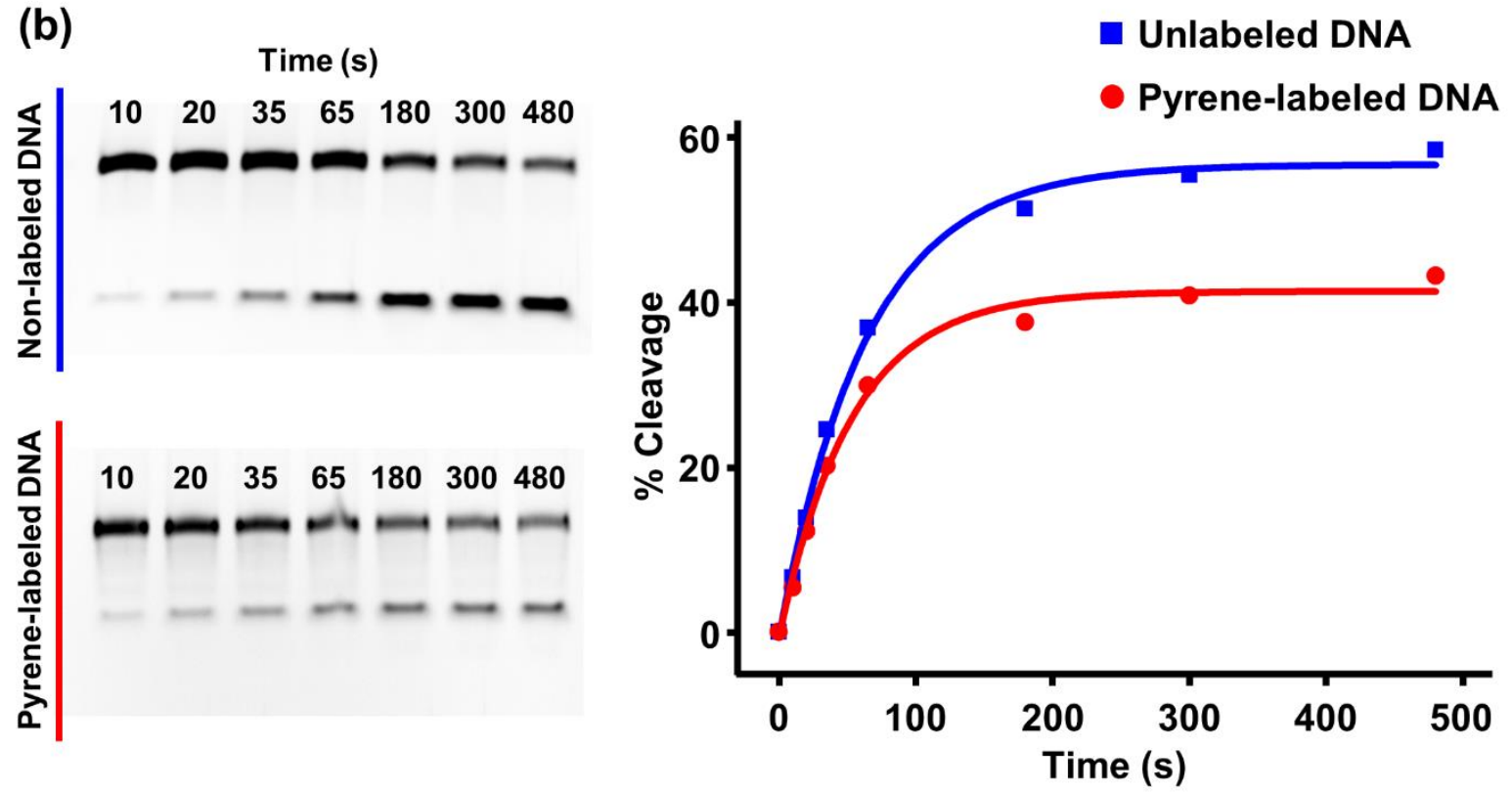

Figure S2 (a) DNA binding assay and (b) cleavage assay, carried out to test the effect of pyrene labeling on the Cas9 activity. The results show that pyrene labeling moderately affect the binding affinity and saturated level of DNA cleavage. Concentrations of DNA and Cas 9 are 200 nM and $400 \mathrm{nM}$, respectively. (c) Cleavage rates obtained by single exponential fitting of the curves in Figure S2b for unlabeled DNA (blue) and pyrene-labeled DNA (red). The result shows that pyrene labeling does not affect the cleavage rate of Cas9 for all on- and off-targets (M20-20 and M1920). These results suggest that pyrene-based probe can be applied to the observation of kinetic rates. Error bars are standard errors of exponential fitting. 


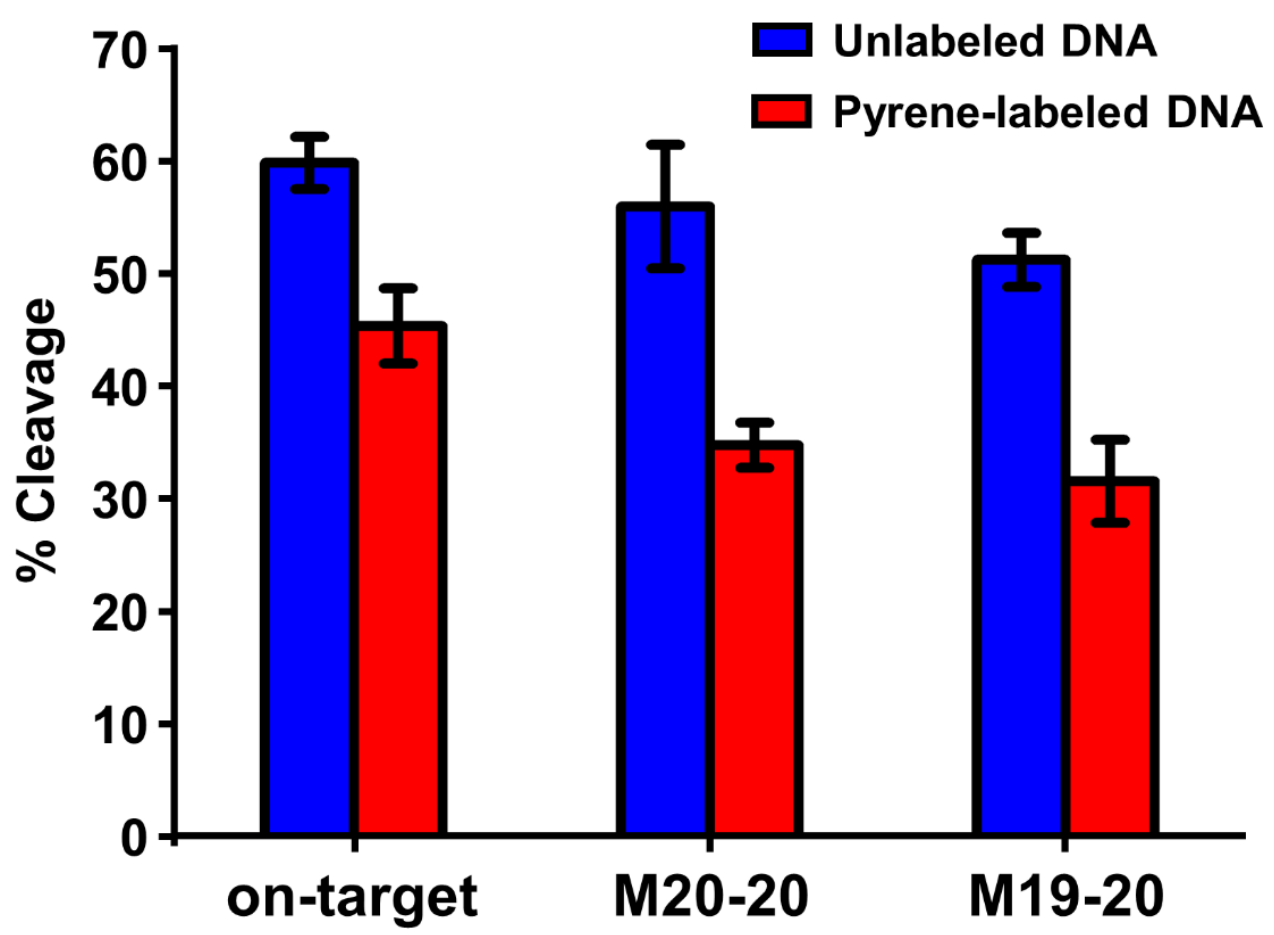

Figure S3 Cleavage efficiencies of the saturated Cas9 for on- and off-targets (M20-20 and M1920). Unlabeled or pyrene-labeled DNA was incubated with each Cas9/gRNA for 15 minutes. Error bars, s.d.; $n=2$. 
(a)

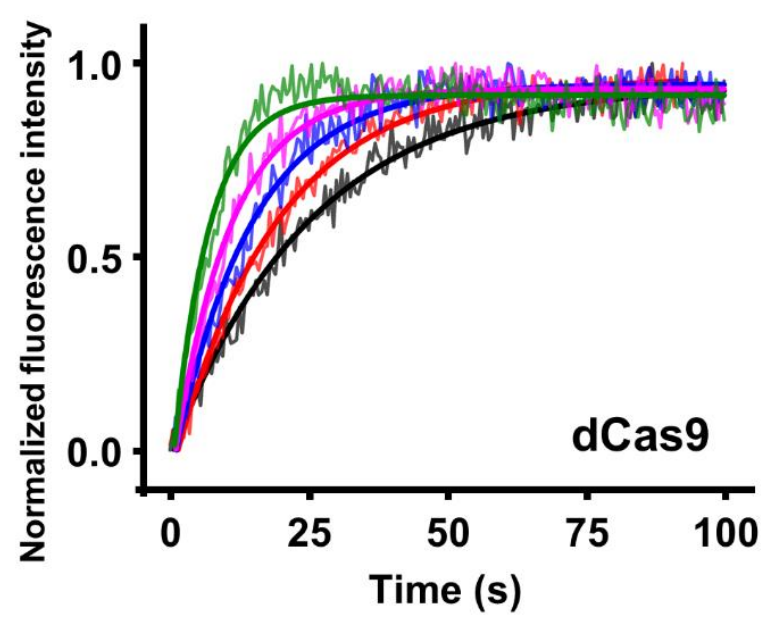

Time (s) (b)

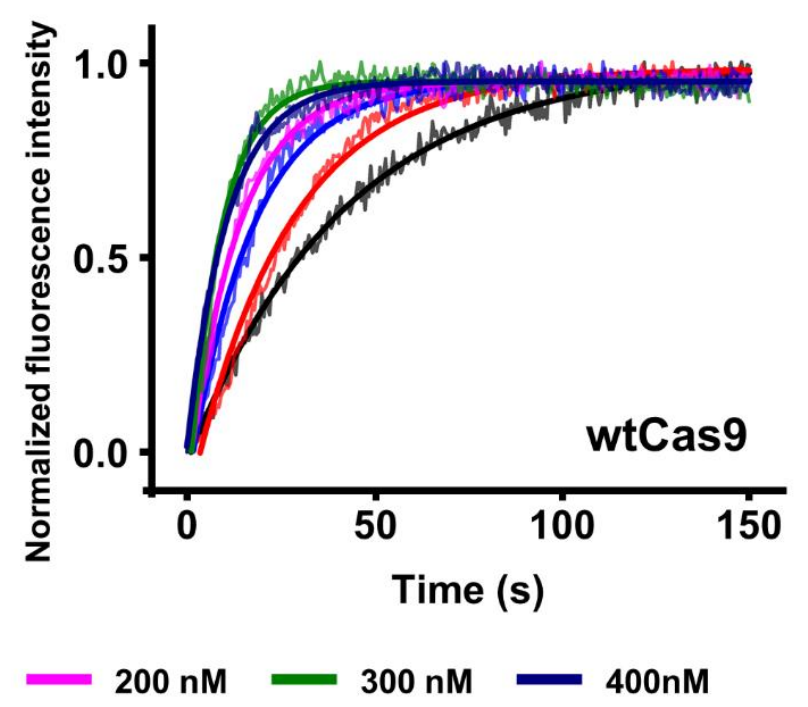

Figure S4 Temporal increase of the intensity of excimer emission from pyrene-labeled DNA upon addition of different concentrations of (a) dCas $9 / g R N A$ and (b) wtCas9/gRNA containing on-target crRNA. Solid lines represent single exponential fits and the observed rate constant is shown in Figure 2(b) and (c). DNA concentration is $20 \mathrm{nM}$ and Cas9 concentration is indicated with colors. 
(a)

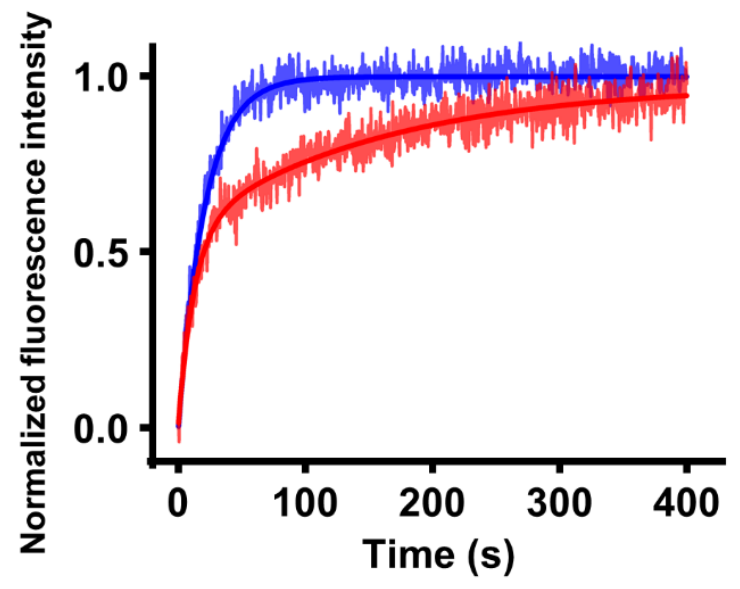

(b)

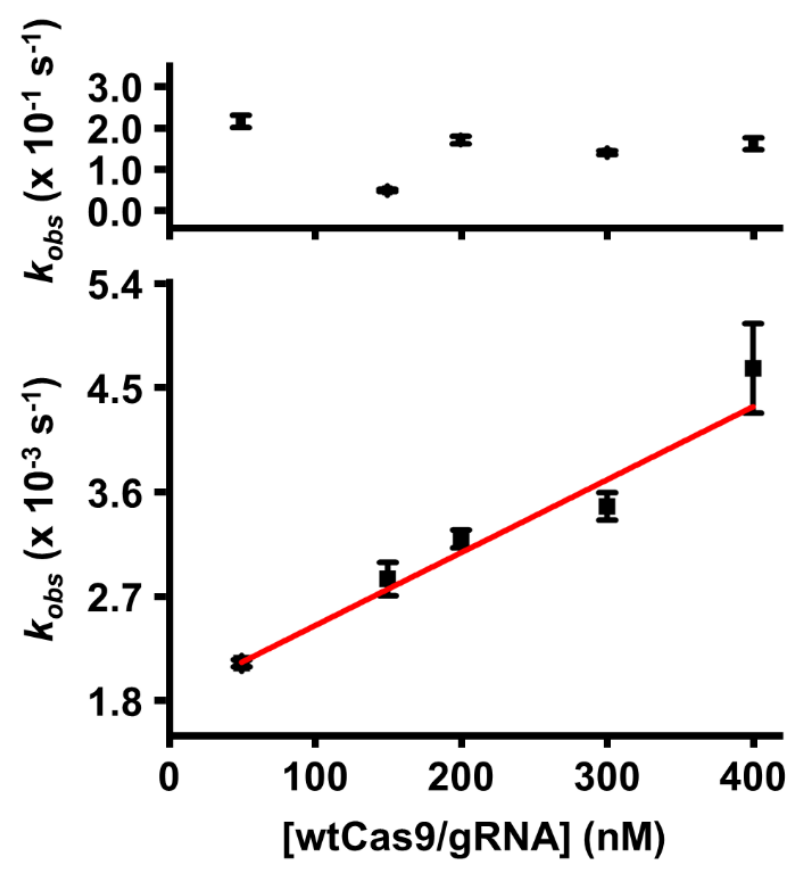

Figure S5 (a) Temporal increase of the intensity of excimer emission from pyrene-labeled DNA upon addition of dCas9/gRNA containing on-target crRNA at room temperature with $10 \mathrm{mM} \mathrm{Mg}{ }^{2+}$ ion (blue) and of wtCas9/gRNA at $37^{\circ} \mathrm{C}$ in the absence of $\mathrm{Mg}^{2+}$ ion (red) fitted to a single exponential curve and bi-exponential curve, respectively. Concentrations of DNA and Cas9 are $20 \mathrm{nM}$ and $200 \mathrm{nM}$, respectively. (b) Since only the rate of the slow phase is dependent on [Cas9/gRNA], $k_{\text {binding }}$ and $k_{\text {unbinding }}$ are determined from the linear fit of the slow component to $k_{\text {obs }}=k_{\text {unbinding }}+k_{\text {binding }} \cdot[\mathrm{Cas} 9 / \mathrm{gRNA}],{ }^{6}$ which yields $k_{\text {binding }}=(0.83 \pm 0.20) \times 10^{4} \mathrm{M}^{-1} \mathrm{~s}^{-1}$ and $k_{\text {unbinding }}=(1.59 \pm 0.24) \times 10^{-3} \mathrm{~s}^{-1}$, in good agreement with those reported previously $\left(k_{\text {binding }}=\sim 1\right.$ $\times 10^{4} \mathrm{M}^{-1} \mathrm{~s}^{-1}$ and $\left.k_{\text {unbinding }}=\sim 1 \times 10^{-3} \mathrm{~s}^{-1}\right) \cdot{ }^{6,7}$ Error bars are standard errors of bi-exponential fitting and the errors of $k_{\text {binding }}$ and $k_{\text {unbinding }}$ are s.e.m.; $\mathrm{n}=2$. 


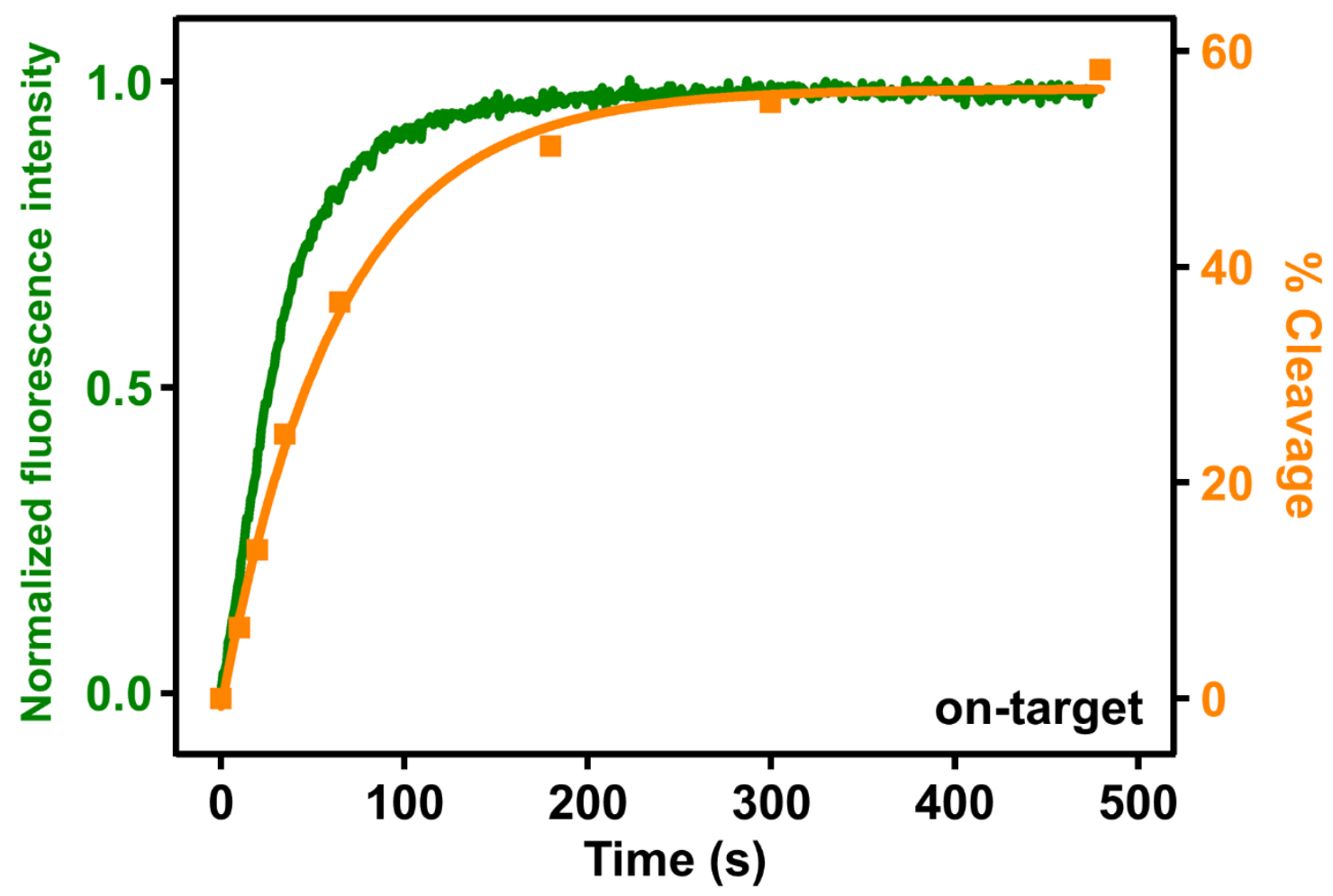

Figure S6 Comparison between the temporal evolution of the intensity of excimer emission (green) and the time-resolved cleavage efficiency measured by gel electrophoresis (orange) for the ontarget DNA. A good agreement between the two curves suggests that the fraction of the intermediate state should be negligible and the main origin of the excimer emission is the complex containing the cleaved DNA. Concentrations of DNA and Cas9 are $200 \mathrm{nM}$ and $400 \mathrm{nM}$, respectively. 
(a)

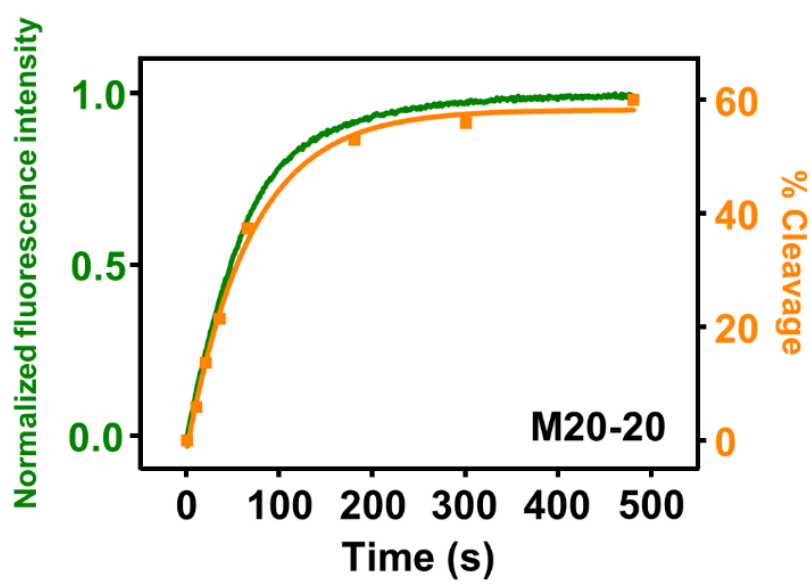

(b)

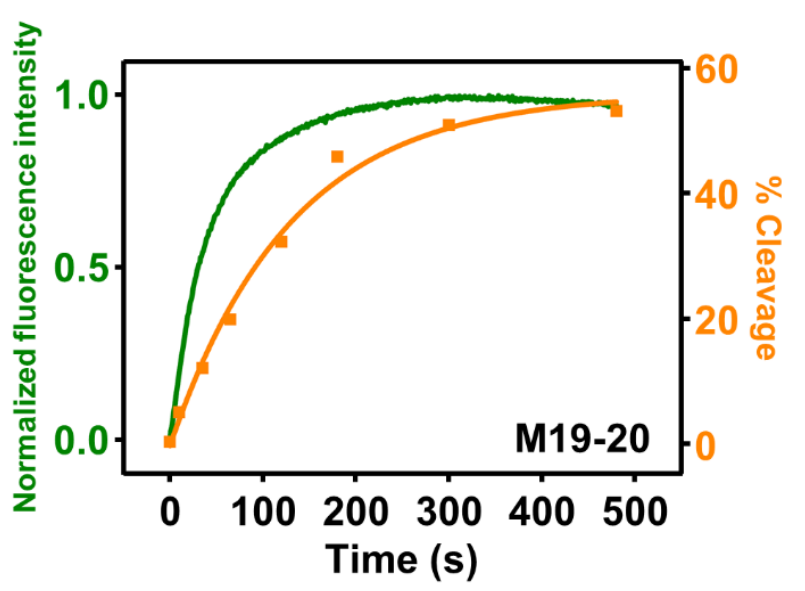

Figure S7 Comparison between the temporal evolution of the intensity of excimer emission (green) and the time-resolved cleavage efficiency measured by gel electrophoresis (orange) for (a) M2020 and (b) M19-20. While the agreement is excellent in the case of M20-20, it is rather poor for M19-20, most likely due to an increase in the population of the intermediate state..$^{1,8-12}$ To address the effect of the intermediate state on calculating the kinetic rate constants, we employed transient-state kinetic model (Figure S9). Concentrations of DNA and Cas9 are 200 nM and 400 $\mathrm{nM}$, respectively. 
(a)

(b)
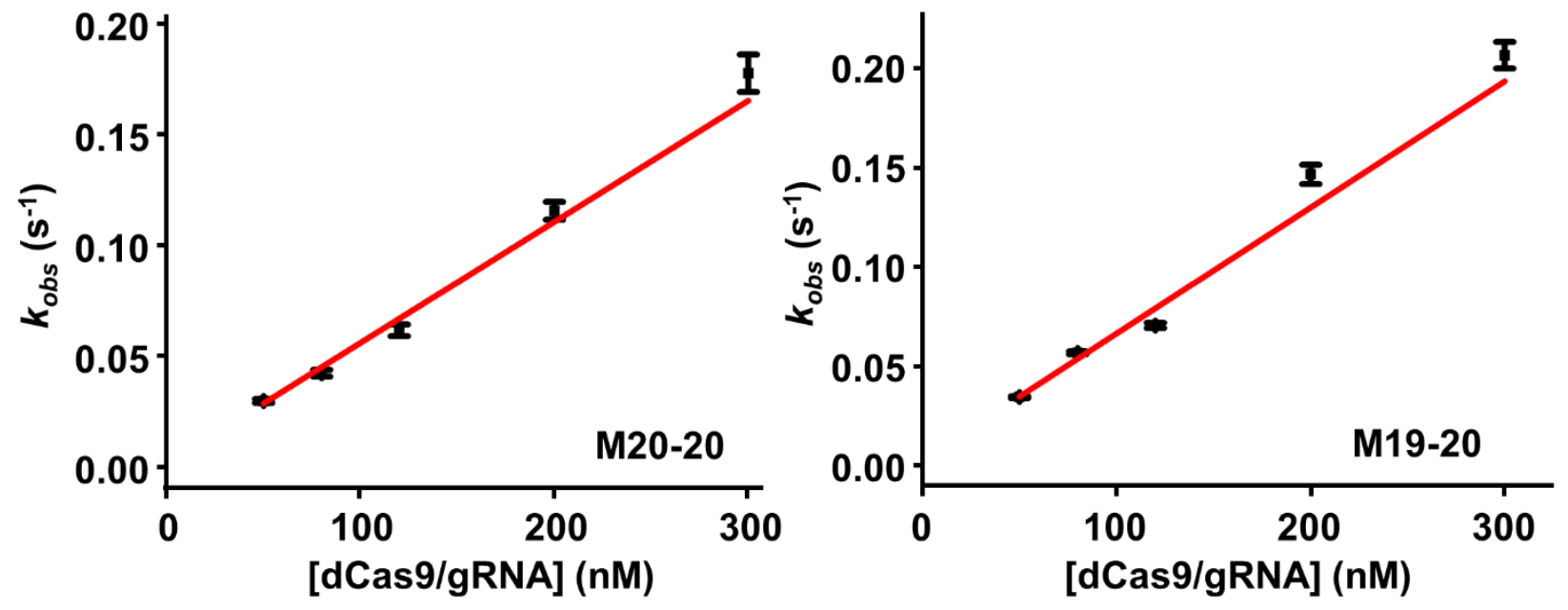

(c)

(d)
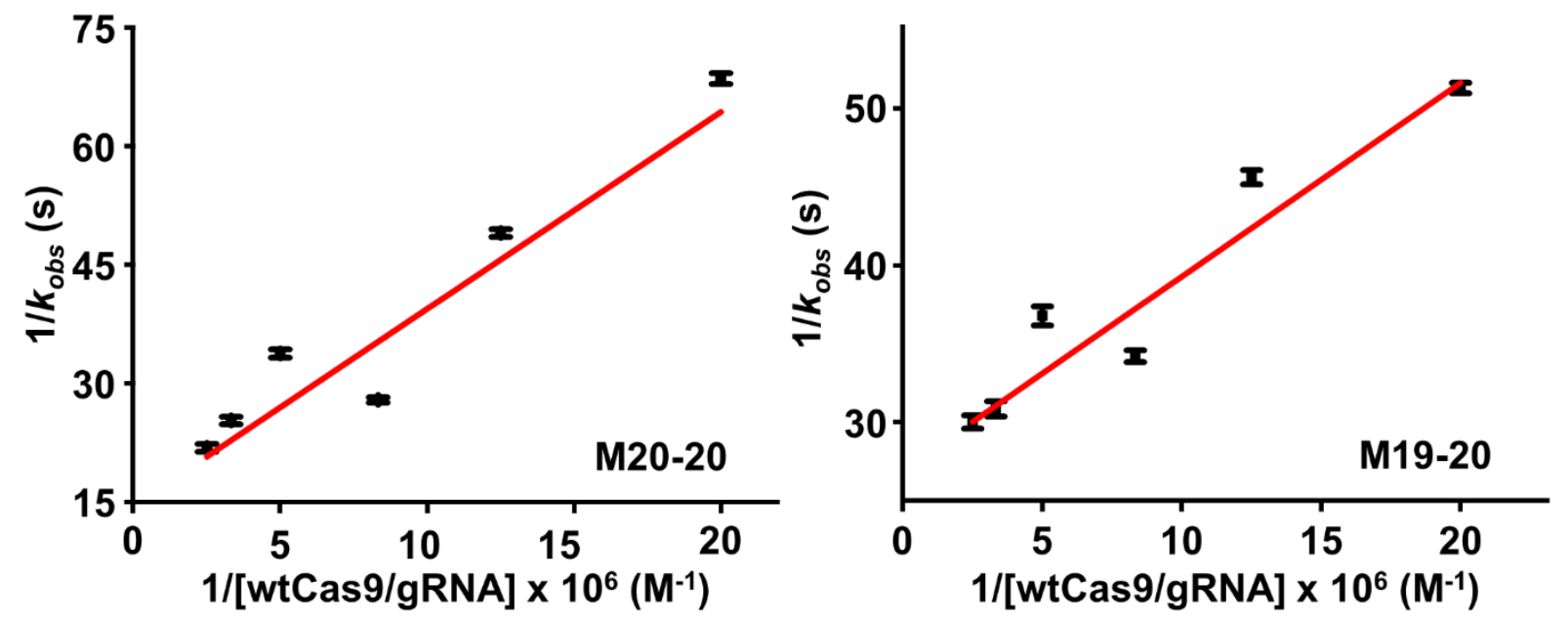

Figure S8 (a-b) Fitting of $k_{o b s}$ as a linear function of the concentration of dCas9/gRNA for (a) M2020 and (b) M19-20. (c-d) Fitting of $1 / k_{o b s}$ as a linear function of the inverse of the concentration of wtCas9/gRNA for (c) M20-20 and (d) M19-20. Error bars are standard errors of exponential fitting. 
(a)
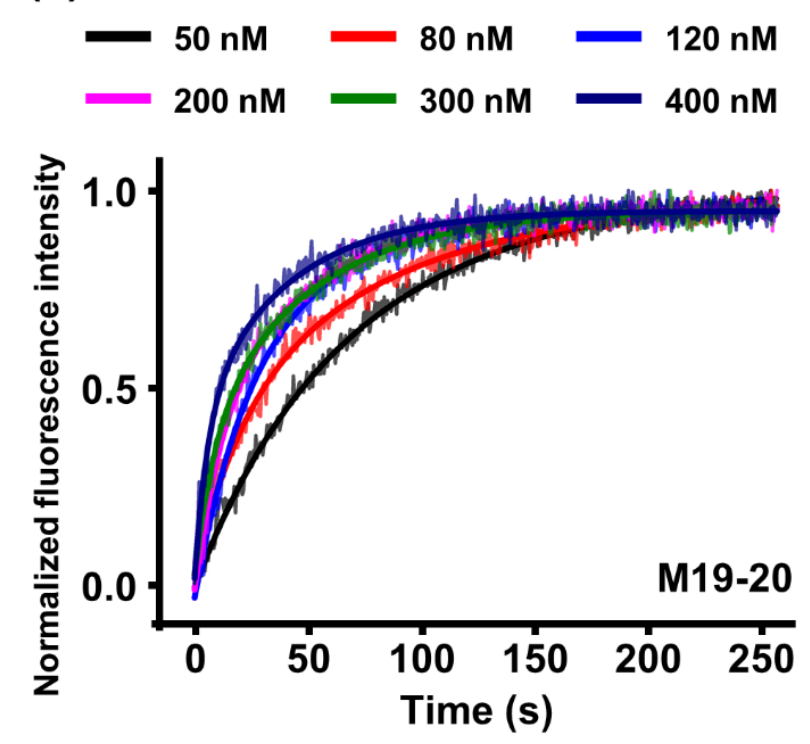

(b)

(c)
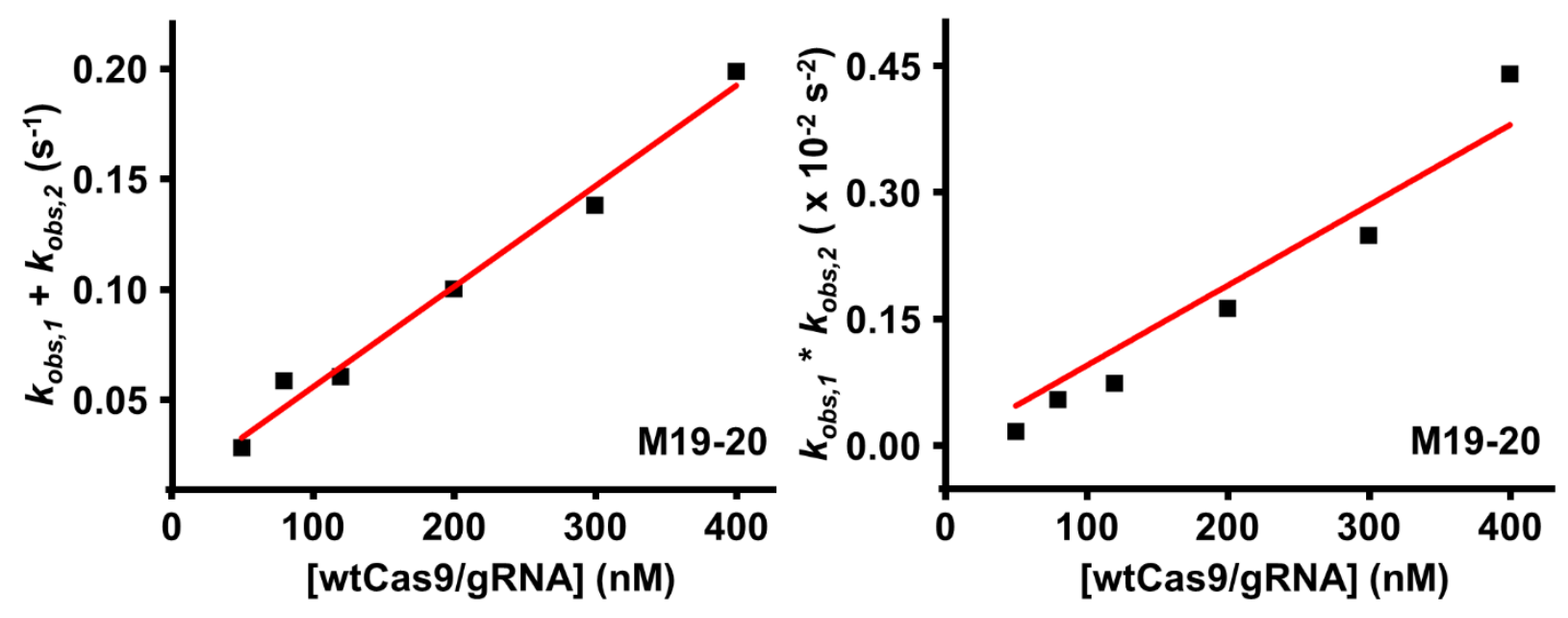

Figure S9 (a) Temporal increase of the intensity of excimer emission from pyrene-labeled DNA upon addition of wtCas9/gRNA containing M19-20 crRNA. Solid lines represent bi-exponential fits, with fast and slow rate constants, $k_{o b s, 1}$ and $k_{o b s, 2}$, respectively. DNA concentration is $20 \mathrm{nM}$ and Cas9 concentration is indicated with colors. (b-c) According to previous single-molecule studies, ${ }^{1,8-12}$ the relative population of the intermediate state exceeds $20 \%$ for M19-20, which may likely invalidate application of the steady-state approximation in our single-turnover model. Since our pyrene probe detects such intermediates, as demonstrated in the case of dCas9/gRNA binding, it will naturally result in a higher intensity of excimer emission (Figure S7(b)). To address the effect of the intermediate state on calculating the kinetic rate constants for M19-20, we applied 
the transient-state kinetics model, where the temporal change in the intensity of excimer emission is described by a bi-exponential curve with two rate constants, $k_{o b s, 1}$ and $k_{o b s, 1}$ (Figure S9(a)).

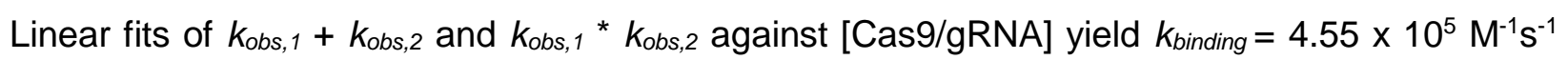
and $k_{\text {cleavage }}=0.021 \mathrm{~s}^{-1}$, which compare well with the values from Figure $3\left(k_{\text {binding }}=5.72 \times 10^{5} \mathrm{M}^{-}\right.$ ${ }^{1} \mathrm{~s}^{-1}$ and $\left.k_{\text {cleavage }}=0.041 \mathrm{~s}^{-1}\right)$. 
Table S1. Sequence list for DNA and RNA constructs. The mismatched bases in the off-target crRNA sequences are colored in red.

\begin{tabular}{|c|c|c|}
\hline Description & Sequences & Notes \\
\hline DNA_TS_py & $\begin{array}{l}\text { 5'- GAT GTG ATG TGT GCC TT [Pyrene-dU] C [Pyrene-dU] TCT } \\
\text { TCA GCT CGG ACT CAG GCA CTT CCT C -3' }\end{array}$ & $\begin{array}{c}\text { Fig. } 1-3, \\
\text { Fig. S2-S9, } \\
\text { Table S2 }\end{array}$ \\
\hline DNA_NTS & $\begin{array}{l}\text { 5'- TTT TTT GAG GAA GTG CCT GAG TCC GAG CTG AAG AAG } \\
\text { AAA GGC ACA CAT CAC ATC -3' }\end{array}$ & $\begin{array}{c}\text { Fig. 1-3, } \\
\text { Fig. S2-S9, } \\
\text { Table S2 }\end{array}$ \\
\hline on-target crRNA & $\begin{array}{l}\text { 5'- GAG UCC GAG CUG AAG AAG AAG UUU UAG AGC UAU } \\
\text { GCU GUU UUG -3' }\end{array}$ & $\begin{array}{l}\text { Fig. 1-3, } \\
\text { Fig. S2-S6 }\end{array}$ \\
\hline M20-20 crRNA & $\begin{array}{l}\text { 5'- CAG UCC GAG CUG AAG AAG AAG UUU UAG AGC UAU GCU } \\
\text { GUU UUG -3' }\end{array}$ & $\begin{array}{c}\text { Fig. 2-3 } \\
\text { Fig. S2, S3, } \\
\text { S7, S8 } \\
\text { Table S2 } \\
\end{array}$ \\
\hline M19-20 crRNA & $\begin{array}{l}\text { 5'- CUG UCC GAG CUG AAG AAG AAG UUU UAG AGC UAU } \\
\text { GCU GUU UUG -3' }\end{array}$ & $\begin{array}{c}\text { Fig. } 2-3, \\
\text { Fig. S2, S3, } \\
\text { S7-S9, } \\
\text { Table S2 }\end{array}$ \\
\hline $\begin{array}{l}\text { Highly off-target } \\
\text { crRNA }\end{array}$ & $\begin{array}{l}\text { 5'- UGG AUG GAG GAA UGA GGA GUG UUU UAG AGC UAU } \\
\text { GCU GUU UUG -3' }\end{array}$ & Fig. 2 \\
\hline tracrRNA & $\begin{array}{l}\text { 5'-AGC AUA GCA AGU UAA AAU AAG GCU AGU CCG UUA UCA } \\
\text { ACU UGAAAA AGU GGC ACC GAG UCG GUG CUU U- 3' }\end{array}$ & $\begin{array}{c}\text { Fig. 1-3, } \\
\text { Fig. S2-S9, } \\
\text { Table S2 }\end{array}$ \\
\hline ssDNA_py & 5'- TTT CGG AAT TCC [Pyrene-dU] T [Pyrene-dU] G -3' & Fig. S1 \\
\hline DNA_comp & 5'- CAA AGG AAT TCC GAAA -3' & Fig. S1 \\
\hline RNA_comp & 5'- CAAAGG AAU UCC GAAA -3' & Fig. S1 \\
\hline DNA_NTS_cy3 & $\begin{array}{l}\text { 5'- TTT TTT GAG GAA GTG CCT GAG TCC GAG C[Cy3-dT]G AAG } \\
\text { AAG AAA GGC ACA CAT CAC ATC -3' }\end{array}$ & Fig. S2 \\
\hline DNA_TS_cy5 & $\begin{array}{l}\text { 5'- GAT GTG ATG TGT GCC [Cy5-dT]T TCT TCT TCA GCT CGG } \\
\text { ACT CAG GCA CTT CCT C -3' }\end{array}$ & $\begin{array}{l}\text { Fig. S2-S3, } \\
\text { S6-S7 }\end{array}$ \\
\hline DNA_TS_py_cy5 & $\begin{array}{l}\text { 5'- GAT GTG ATG TGT GCC [Cy5-dT]T [Pyrene-dU] C [Pyrene-dU] } \\
\text { TCT TCA GCT CGG ACT CAG GCA CTT CCT C -3' }\end{array}$ & $\begin{array}{l}\text { Fig. S2-S3, } \\
\text { S6-S7 }\end{array}$ \\
\hline
\end{tabular}


Table S2. Result for the kinetic rate constants for on-target and off-targets. The results are shown at a mean \pm s.e.m. $(n=3)$

\begin{tabular}{|c|c|c|c|}
\hline & kbinding $\left(\times 10^{5} \mathrm{M}^{-1} \mathrm{~s}^{-1}\right)$ & $k$ unbinding $\left(\mathrm{s}^{-1}\right)$ & $k_{\text {cleavage }}\left(\mathrm{s}^{-1}\right)$ \\
\hline on-target & $4.91 \pm 0.63$ & $0.0119 \pm 0.0100$ & $0.153 \pm 0.024$ \\
\hline M20-20 & $5.22 \pm 0.51$ & $0.0085 \pm 0.0048$ & $0.053 \pm 0.002$ \\
\hline M19-20 & $5.72 \pm 0.57$ & $0.0154 \pm 0.0073$ & $0.041 \pm 0.005$ \\
\hline
\end{tabular}




\section{References for the Supporting Information}

(1) Sung, K.; Park, J.; Kim, Y.; Lee, N. K.; Kim, S. K. Target Specificity of Cas9 Nuclease via DNA Rearrangement Regulated by the REC2 Domain, J. Am. Chem. Soc., 2018, 140, 7778-7781.

(2) Hwang, H.; Kim, H.; Myong, S. Protein Induced Fluorescence Enhancement as a Single Molecule Assay with Short Distance Sensitivity, Proc. Natl. Acad. Sci. USA, 2011, 108, 7414-7418.

(3) Valuchova, S.; Fulnecek, J.; Petrov, A. P.; Tripsianes, K.; Riha, K. A. A Rapid Method for Detecting Protein-Nucleic Acid Interactions by Protein Induced Fluorescence Enhancement. Sci. Rep., 2016, 6, 39653.

(4) Drew, H. R.; Wing, R. M.; Takano, T.; Broka, C.; Tanaka, S.; Itrakura, K.; Dickerson, R. E. Structure of a B-DNA Dodecamer: Conformation and Dynamics, Proc. Natl. Acad. Sci. USA., 1981, 78, 2179-2183.

(5) Gyi, J. I.; Lane, A. N.; Conn, G. L.; Brown, T. Solution Structures of DNA-RNA Hybrids with Purine-Rich and Pyrimidine-Rich Strands: Comparison with the Homologous DNA and RNA Duplexes, Biochemistry, 1998, 37, 73-80.

(6) Raper, A. T.; Stephenson, A. A.; Suo, Z. Functional Insights Revealed by the Kinetic Mechanism of CRISPR/Cas9, J. Am. Chem. Soc., 2018, 140, 2971-2984.

(7) Gong, S.; Yu, H. H.; Johnson, K. A.; Taylor, D. W. DNA Unwinding Is the Primary Determinant of CRISPR-Cas9 Activity, Cell Rep., 2018, 22, 359-371.

(8) Singh, D.; Sternberg, S. H.; Fei, J.; Doudna, J. A.; Ha, T. Real-time Observation of DNA Recognition and Rejection by the RNA-guided Endonuclease Cas9, Nat. Commun., 2016, 7, 12778.

(9) Lim, Y.; Bak, S. Y.; Sung, K.; Jeong, E.; Lee, S. H.; Kim, J. -S.; Bae, S.; Kim, S. K. Structural Roles of Guide RNAs in the Nuclease Activity of Cas9 Endonuclease, Nat. Commun., 2016, 7, 13350.

(10) Dagdas, Y. S.; Chen, J. S.; Sternberg, S. H.; Doudna, J. A.; Yildiz, A. A Conformational Checkpoint between DNA Binding and Cleavage by CRISPR-Cas9, Sci. Adv., 2017, 3, eaao0027.

(11) Singh, D.; Wang, Y.; Mallon, J.; Yang, O.; Fei, J.; Poddar, A.; Ceylan, D.; Bailey, S.; Ha, T. Mechanisms of Improved Specificity of Engineered Cas9s Revealed by Single-molecule FRET analysis, Nat. Struct. Mol. Biol., 2018, 25, 347-354.

(12) Cromwell, C. R.; Sung, K.; Park, J.; Krysler, A. R.; Jovel, J.; Kim, S. K.; Hubbard, B. P. Incorporation of Bridged Nucleic Acids into CRISPR RNAs Improves Cas9 Endonuclease Specificity, Nat. Commun., 2018, 9, 1448. 